\title{
Springback of I-Section Beam after Pure Bending with von Mises Criteria
}

\author{
Reham Saleh1', Gamal Ali², Abla El-Megharbel² \\ ${ }^{1}$ Port Said, Egypt \\ ${ }^{2}$ Department of Production Engineering, Port Said University, Port Said, Egypt \\ Email: engrehamsaleh1@gmail.com,gamal_osmun@yahoo.com, aelmegharbel@eng.psu.edu.eg
}

How to cite this paper: Saleh, R., Ali, G. and El-Megharbel, A. (2018) Springback of I-Section Beam after Pure Bending with von Mises Criteria. World Journal of Engineering and Technology, 6, 104-118. https://doi.org/10.4236/wjet.2018.61006

Received: December 21, 2017

Accepted: January 30, 2018

Published: February 2, 2018

Copyright $\odot 2018$ by authors and Scientific Research Publishing Inc. This work is licensed under the Creative Commons Attribution International License (CC BY 4.0).

http://creativecommons.org/licenses/by/4.0/

\begin{abstract}
The objective of the present paper is to introduce a theoretical analysis of bending I-sections after pure bending. The springback values are determined to provide a quantitative method for predicting the springback using von Mises criteria. The analytical methods for the I-section are given for two cases according to the positions of the yield point along the height of the beam. The controlling parameters on the springback of I-sections are studied. The results obtained are quite successful for the prediction of springback for bending I-sections.
\end{abstract}

\section{Keywords}

Bending Sections, Beam, Springback, von Mises

\section{Introduction}

Production of different sections has a great significance in the industry, because of the importance of these sections in various industries such as aerospace, trains, ships and various industrial purposes. In every industry, quality and productivity are major issues for being competitive. For example, a car frame needs to be designed to achieve strength requirements and aesthetic aspects; on the other hand, cost of production and repeatability is crucial to the business. A bending process has been one solution used in practice to achieve these goals in the sheet metal fabrication business. However, springback, a shape discrepancy between the fully loaded and unloaded configurations, undermines the stamping benefits, since a major effort on the tooling design is needed to compensate springback, so the bending process of forming is the most important operations at all. During bending process, the elastic recovery after unloading causes 
springback phenomenon. Therefore determination of springback in bending process is of great significance as it is used in the die design, geometry of the parts. This leads us to try to find the appropriate prediction of springback to reduce and control it. Many researchers have studied springback in different sections and factors controlling it. Researcher [1] presents a simple mathematical model for estimating the moment, springback and residual stresses in the pure bending of thin-walled aluminum tubes. Wang and his colleagues [2] have investigated the size effect in micro-Unbending process on the copper alloy sheet C2680 R-H used three kinds of copper sheet metal with different thickness to explore the influence of grain size effect and the thickness effect on the springback. Fang and his colleagues [3] have studied the effect of grain size on the springback using FE simulation, where they displayed the inhomogeneous deformation during micro V-bending process and showed that springback increases with grain size. Moon and his team [4] have studied the effect of the tool temperature on the reduction of springback amount of aluminum 1050 sheet. The experimental results showed that the combination of hot die and cold punch can reduce the amount of springback up to $20 \%$ compared to conventional room temperature bending test. Reference [5] has evaluated the elastic springback and residual stress after stretch bending of rectangular section of 7075 aluminum sheet. Also [6] introduced the mathematical models that can be used to calculate the bending moment, the springback and residual stresses for any curvature of work hardening tube with different shapes. On the other hand, Mertin and Hirta [7] made numerical and experimental investigations on the springback behaviour of stamping and bending parts. They had investigated the tool geometries and kinematics influencing the bending results in multi-stage stamping and bending processes. Leu and his colleagues [8] have predicted the amount of springback reduction resulted from the coining force in V-die bending with a new model including material and geometrical characteristics. Manach and his colleagues [9] have investigated the bending and springback behavior on AA6111-T4 aluminum alloy and high strength steel using experimental test to determine the effect of plastic strain on the springback phenomenon. Panthi and his colleagues [10] have studied the influence of geometric parameters such as die radius, thickness of the sheet and sector angle, mechanical material properties such as yield strength, young modulus and strain-hardening exponent and lubrication condition. In this study, they predict the springback behavior by the elastic-plastic analysis of sheet metal bending process using RRL-FEM software. Zhao and his colleagues [11] have studied the springback on stretch bending of profile with rectangular cross section, U-section in the loading method of pretension and moment. In another research of Zhao and his team [12], they have made the plane curved beam with any cross section as a study object carried out a systematic theoretical study based on the unloading law of classical elastic plastic theory and the characteristic of strain super position. The plane bending geometric constraints equation and the springback equation were also derived. 
Song and his colleagues [13] have predicted model of springback in T-section beam bending process using artificial neural network approach. The relationship between the loading stroke and springback stroke has also analyzed the effect of the material properties on the springback. While T-Liu and his colleagues [14] have investigated the springback behaviors on 2196-T8511 and 2099-T83 Al-Li alloys extrusions under displacement controlled cold stretch bending. Both the analytical and FE model are validated by the experimental, which resulted that the radius springback ratio decreased with the increasing pre-stretching and post-stretching. Patel and his colleagues [15] have analyzed the springback in sheet metal forming. They predicted the springback equation using modified Ludwik stress-strain relation with Tresca and von Mises yield criteria. Meanwhile, Leu and Zhuang [16] had developed a simplified approach by considering the thickness ratio, normal anisotropy, and the strain-hardening exponent to estimate the springback of vee bending based on elementary bending theory.

Springback values for I-section beam have been determined with the assumption of yielding according to Tresca criteria as shown by [17]. This assumption is not completely valued for large plastic, therefore von Mises criteria are used in the present work. The controlling parameters such as, material properties, strain hardening exponent and height of the beam have been studied, as well as their influence on the springback behavior. Moreover, a comparison between Tresca and von Mises yielding criteria has been carried out.

\section{Numerical Analysis}

In this paper, analysis of springback for I-section under bending is done to predict the springback values. The stress-strain relationship is $\sigma=E \varepsilon$ is in the elastic range and $\sigma=K \varepsilon^{n}$ is in the plastic range. Where $\sigma$ is the bending stress, $\varepsilon$ is the bending strain, $Y$ is the yield strength, $E$ is the modulus of elastically, $K$ is the strength coefficient and $\mathrm{n}$ is the strain hardening exponent.

Figure 1 shows the relation between the applied bending moments on I-section to the change in curvature. At point A the material yields, at maximum bending moment the material undergoes to plastic deformation. At point $\mathrm{B}$, when the applied moment is released elastic springback occurs from point $B$ to

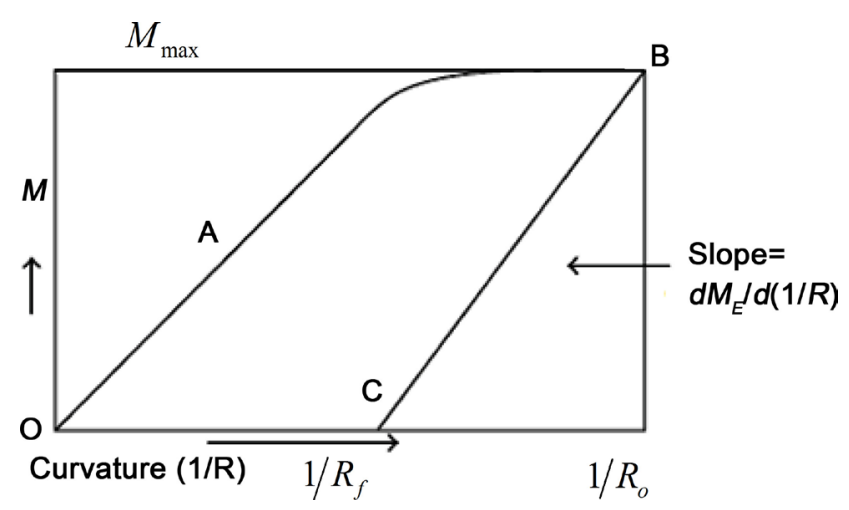

Figure 1. The relation between applied bending moments and curvature. 
point $\mathrm{C}$. The change in curvature due to elastic springback is given by the following equation:

$$
\frac{1}{R_{o}}-\frac{1}{R_{f}}=\frac{M_{\max }}{\partial M_{E} / \partial(1 / R)} .
$$

where $R_{o}$ is the required radius and $R_{f}$ is the final radius

Assumptions are considered to derivation the springback equation for I-section beam (Figure 2) according to von Mises yielding criteria:

1) The friction effect in the interface between the beam and the die is neglected.

2) The cross section dimension of the beam are such as the width to height ratio is height.

3) The stress-strain characteristic of material is the same in the tension and compression.

4) The cross section dimension of the beam do not change significantly in bending.

5) The radius of bending is large compared to the height of the beam so radial stresses are assumed is negligible.

6) The natural surface is always in the center of the beam, and plane section remains plane during bending.

7) The transverse strain is zero at any point in the plane.

8) The circumferential strains are sufficiently small so that the conventional strain and the strain are approximately equivalent.

9) The circumferential strain for any fiber does not vary along the bent section.

The general relationship between principle stresses and strain for elastic deformation is given by:

$$
\varepsilon_{x}=\frac{1}{E}\left(\sigma_{x}-v\left(\sigma_{y}+\sigma_{z}\right)\right) .
$$

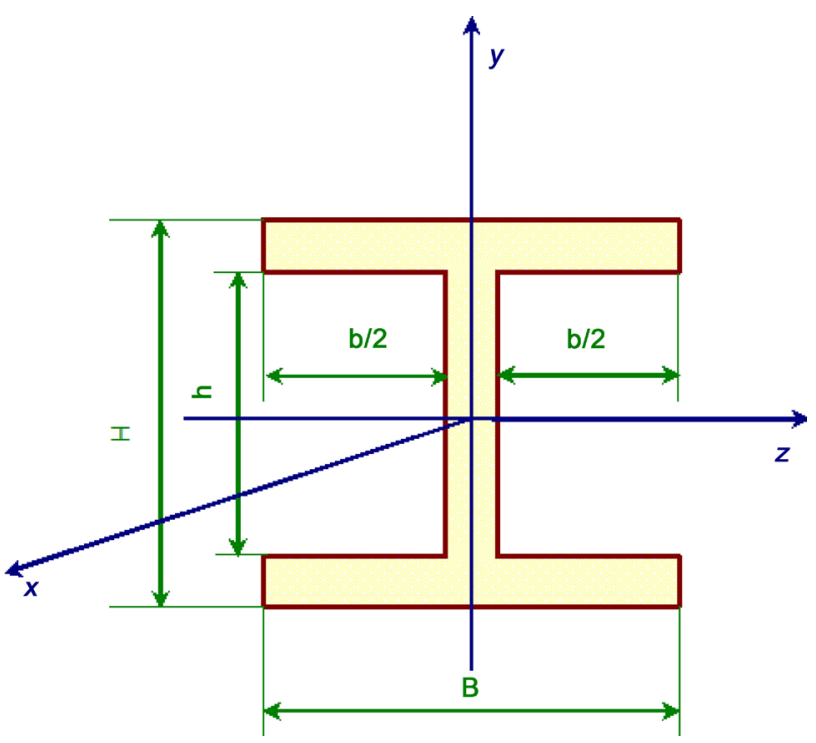

Figure 2. I-section of the beam as a case study [17]. 


$$
\begin{gathered}
\varepsilon_{y}=\frac{1}{E}\left(\sigma_{y}-v\left(\sigma_{x}+\sigma_{z}\right)\right) . \\
\varepsilon_{z}=\frac{1}{E}\left(\sigma_{z}-v\left(\sigma_{y}+\sigma_{x}\right)\right) .
\end{gathered}
$$

From the assumption that:

$$
\sigma_{y}=\varepsilon_{z}=\delta_{z}=0 .
$$

Then,

$$
\sigma_{z}=v \sigma_{x} .
$$

From maximum shear stress theory of failure (von Mises yield criteria),

$$
\sigma_{o}^{2}=\frac{1}{2}\left(\left(\sigma_{x}-\sigma_{y}\right)^{2}+\left(\sigma_{y}-\sigma_{z}\right)^{2}+\left(\sigma_{z}-\sigma_{x}\right)^{2}\right) .
$$

Substitute Equations ((2) and (4)) in Equation (5), yields

$$
\sigma_{o}=\sigma_{x}\left(1+v^{2}-v\right)^{\frac{1}{2}} .
$$

Stress in yield point is

$$
\begin{gathered}
\sigma_{o}=K\left(\frac{K}{E}\right)^{\frac{n}{1-n}}=\sigma_{x}\left(1+v^{2}-v\right)^{\frac{1}{2}} . \\
\sigma_{o x}=\frac{K\left(\frac{K}{E}\right)^{\frac{n}{1-n}}}{\left(1+\mathcal{V}^{2}-\mathcal{V}\right)^{\frac{1}{2}}} . \\
\varepsilon_{x}=\left(\frac{1}{E}\right) \sigma_{x}\left(1-v^{2}\right) .
\end{gathered}
$$

So, in the yield point the axial strain is,

$$
\varepsilon_{o x}=\left(\frac{1}{E}\right) \sigma_{o x}\left(1-v^{2}\right) .
$$

Substitute with the yield point stress value in the equation

$$
\varepsilon_{o x}=\left(\frac{K}{E}\right)^{\frac{1}{1-n}} \frac{\left(1-\mathcal{V}^{2}\right)}{\left(1+\mathcal{V}^{2}-\mathcal{V}\right)^{\frac{1}{2}}} .
$$

This is approximate value of axial strain elastic-plastic interface, then, in the elastic region the axial stress is,

$$
\sigma_{x}=\frac{E}{\left(1-\mathcal{V}^{2}\right)} \varepsilon_{x} .
$$

where

$$
\varepsilon_{x}=\frac{y}{R_{o}} .
$$

Substitute with the circumferential strain, gives 


$$
\sigma_{x}=\frac{E}{\left(1-\mathcal{V}^{2}\right)}\left(\frac{y}{R_{o}}\right) \text { for } 0 \leq \varepsilon_{x} \leq\left(\frac{K}{E}\right)^{\frac{1}{1-n}} \frac{\left(1-\mathcal{V}^{2}\right)}{\left(1+\mathcal{V}^{2}-\mathcal{V}\right)^{\frac{1}{2}}}
$$

which $\left(\sigma_{x}\right)$ is the axial stress in the elastic region.

From the assumptions, substitute with Equations ((4), (5)) in the previous equation, yields

$$
\begin{gathered}
\sigma_{z}=\frac{\sigma_{x}}{2} . \\
\sigma_{x}=\frac{K}{\left(\frac{3}{4}\right)^{\frac{1+n}{2}}} \delta_{x}^{n} .
\end{gathered}
$$

where $\sigma_{x}$ is valid for plastic region; that is

$$
\left(\frac{K}{E}\right)^{\frac{1}{1-n}} \frac{\left(1-\mathcal{V}^{2}\right)}{\left(1+\mathcal{V}^{2}-\mathcal{V}\right)^{\frac{1}{2}}} \leq \varepsilon_{x} \leq \frac{H}{2}
$$

During the bending forming of the I-section beam the springback behavior occur according to position of the yield point $\left(h^{*}\right)$ the distance from the neutral surface up to the layer at which the yielding occurs so, this point is controlled in the springback behavior. Thus that, the applied bending moment is analyzes to two cases according the position of the yielding point along the beam height.

Case (1), the plastic region is in flange of I-section beam.

Substituting the values of elastic and plastic stress in the general equation of bending moment with considerable the integration limits as the following.

$$
M=2 \int_{0}^{\frac{H}{2}} \sigma_{x} \mathrm{~d} A .
$$

The limits of integration are $0 \rightarrow h / 2$ the distance from the neutral axis to the lower layer of the flange, $h / 2 \rightarrow h^{*}$ the distance from the lower layer of the flange to the yielded point where the plastic deformation occurs and finally, $h^{*} \rightarrow H / 2$ the distance from the yielded point to the upper layer of the flange.

$$
\begin{aligned}
M_{\max }= & 2\left(\int_{0}^{\frac{h}{2}} \sigma_{x_{\text {elassic }}}(B-b) y \mathrm{~d} y+\int_{\frac{h}{2}}^{h^{*}} \sigma_{x_{\text {elastic }}} B y \mathrm{~d} y+\int_{h^{*}}^{\frac{H}{2}} \sigma_{x_{\text {plassic }}} B y \mathrm{~d} y\right) . \\
M_{\max }= & 2\left(\int_{0}^{\frac{h}{2}} \frac{E}{\left(1-\mathcal{V}^{2}\right)} * \frac{y^{2}}{R_{o}}(B-b) \mathrm{d} y+\int_{\frac{h}{2}}^{h^{*}} \frac{E}{\left(1-\mathcal{V}^{2}\right)} * \frac{y^{2}}{R_{o}} B \mathrm{~d} y\right. \\
& \left.+\int_{h^{*}}^{\frac{H}{2}} \frac{K}{\left(\frac{3}{4}\right)^{\frac{1+n}{2}}} \frac{y^{n+1}}{R_{o}^{n}} B \mathrm{~d} y\right)
\end{aligned}
$$

where: 


$$
h^{*}=R_{o}\left(\frac{K}{E}\right)^{\frac{1}{1-n}} \frac{\left(1-\mathcal{V}^{2}\right)}{\left(1+\mathcal{V}^{2}-\mathcal{V}\right)^{\frac{1}{2}}} .
$$

Thus

$$
\begin{aligned}
M_{\max }= & 2\left(\frac{E B R_{o}^{2}}{3\left(1-\mathcal{V}^{2}\right)}\left(\frac{K}{E}\right)^{\frac{3}{1-n}} \frac{\left(1-\mathcal{V}^{2}\right)^{3}}{\left(1+\mathcal{V}^{2}-\mathcal{V}\right)^{\frac{3}{2}}}-\frac{E b}{3\left(1-\mathcal{V}^{2}\right) R_{o}}\left(\frac{h}{2}\right)^{3}\right. \\
& \left.+\frac{K B}{(3 / 4)^{(1+n) / 2}(n+2)}\left(\left(\frac{1}{R_{o}^{n}}\right)\left(\frac{H}{2}\right)^{n+2}-R_{o}^{2}\left(\frac{K}{E}\right)^{\frac{n+2}{1-n}} \frac{\left(1-\mathcal{V}^{2}\right)^{n+2}}{\left(1+\mathcal{V}^{2}-\mathcal{V}\right)^{\frac{n+2}{2}}}\right)\right)
\end{aligned}
$$

The bending equation in the elastic range is

$$
M_{E}=\frac{\sigma_{x} \cdot I_{z}}{y} .
$$

where $I_{z}$, is the moment of inertia for the I-section about the neutral axis.

$$
I_{z}=\frac{B H^{3}}{12}-\frac{b h^{3}}{12} \text {. }
$$

Referring to the springback ratio

$$
\frac{R_{o}}{R_{f}}=1-\frac{M_{\max }}{\partial M_{E} / \partial(1 / R)} * R_{o} .
$$

Yielding:

$$
\begin{aligned}
\frac{R_{o}}{R_{f}}= & 1-\left(\left(\frac{K}{E}\right) \frac{24 B\left(1-\mathcal{V}^{2}\right)}{(3 / 4)^{(1+n) / 2}(n+2)\left(B H^{3}-b h^{3}\right)}\right. \\
& \times\left(\left(\frac{1}{R_{o}^{n}}\right)\left(\frac{H}{2}\right)^{n+2}-R_{o}^{2}\left(\frac{K}{E}\right)^{\frac{n+2}{1-n}} \frac{\left(1-\mathcal{V}^{2}\right)^{n+2}}{\left(1+\mathcal{V}^{2}-\mathcal{V}\right)^{\frac{n+2}{2}}}\right) \\
& \left.-\frac{b h^{3}}{\left(B H^{3}-b h^{3}\right)}-\frac{8 B R_{o}^{3}}{\left(B H^{3}-b h^{3}\right)}\left(\frac{K}{E}\right)^{\frac{3}{1-n}} \frac{\left(1-\mathcal{V}^{2}\right)^{3}}{\left(1+\mathcal{V}^{2}-\mathcal{V}\right)^{\frac{3}{2}}}\right)
\end{aligned}
$$

Assume

$$
\begin{gathered}
\frac{b}{B}=\beta, \frac{h}{H}=\alpha . \\
\frac{R_{o}}{R_{f}}=1-\frac{1}{\left(1-B \alpha^{3}\right)}\left(\frac{3\left(1-\mathcal{V}^{2}\right)}{(3 / 4)^{(1+n) / 2}(n+2)}\left(\frac{2 R_{o}}{H}\right)^{1-n}\left(\frac{\sigma_{o}}{E}\right)^{1-n}-B \alpha^{3}\right. \\
\left.+\left(\frac{2 R_{o}}{H}\right)^{3}\left(\frac{\sigma_{o}}{E}\right)^{3}\left(\frac{\left(1-\mathcal{V}^{2}\right)^{3}}{\left(1+\mathcal{V}^{2}-\mathcal{V}\right)^{\frac{3}{2}}}-\frac{3\left(1-\mathcal{V}^{2}\right)^{n+3}}{(3 / 4)^{(1+n) / 2}(n+2)\left(1-\mathcal{V}+\mathcal{V}^{2}\right)^{\frac{n+2}{2}}}\right)\right)
\end{gathered}
$$


This is the model equation of the springback ratio for I-section beam which the plastic deformation is in the flange according to von Mises yield criteria.

Case (2): the plastic region in the web of I-section beam,

Substituting the values of elastic stress and plastic stress; moreover change the integration limits according to the position of yields point. $\left(0 \rightarrow h^{*}\right)$ is the distance from the neutral axis to the yield point in the web of the I-section beam where the plastic deformation occurs, $\left(h^{*} \rightarrow \frac{h}{2}\right)$ is the distance from the yielding point to the lower surface of the flange, $\left(\frac{h}{2} \rightarrow \frac{H}{2}\right)$ is the distance from the lower surface of the flange to the upper surface of the flange of the beam.

$$
M_{\max }=2\left(\int_{0}^{h^{o e x}} \sigma_{x_{\text {elastic }}}(B-b) y \mathrm{~d} y+\int_{h^{\text {oex }}}^{\frac{h}{2}} \sigma_{x_{\text {plassic }}}(B-b) y \mathrm{~d} y+\int_{\frac{h}{2}}^{\frac{H}{2}} \sigma_{x_{\text {plassic }}} B y \mathrm{~d} y\right) .
$$

where

$$
\begin{aligned}
h^{*}=R_{o}\left(\frac{K}{E}\right)^{\frac{1}{1-n}} \frac{\left(1-\mathcal{V}^{2}\right)}{\left(1+\mathcal{V}^{2}-\mathcal{V}\right)^{\frac{1}{2}}} . \\
M_{\max }=2\left(\frac{E(B-b) R_{o}^{2}}{3\left(1-\mathcal{V}^{2}\right)}\left(\frac{K}{E}\right)^{\frac{3}{1-n}} \frac{\left(1-\mathcal{V}^{2}\right)^{3}}{\left(1+\mathcal{V}^{2}-\mathcal{V}\right)^{\frac{3}{2}}}-\frac{K b}{\left(\frac{3}{4}\right)^{\frac{1+n}{2}}(n+2) R_{0}{ }^{n}}\left(\frac{h}{2}\right)^{n+2}\right. \\
\left.+\frac{K B}{\left(\frac{3}{4}\right)^{\frac{1+n}{2}}(n+2) R_{0}{ }^{n}}\left(\frac{H}{2}\right)^{n+2}-\frac{K(B-b) R_{o}^{2}}{\left(\frac{3}{4}\right)^{\frac{1+n}{2}}\left(\frac{K}{E}\right)^{\frac{n+2}{1-n}} \frac{\left(1-\mathcal{V}^{2}\right)^{n+2}}{\left(1+\mathcal{V}^{2}-\mathcal{V}\right)^{\frac{n+2}{2}}}}\right)
\end{aligned}
$$

Substituting with the Equation (25) in Equation (29), substituting the result equation of the maximum bending moment in the Equation (23), we get the following equation

$$
\begin{aligned}
\frac{R_{o}}{R_{f}}= & 1-\frac{1}{\left(1-\beta \alpha^{3}\right)}\left(\frac{3\left(1-\mathcal{V}^{2}\right)}{\left(\frac{3}{4}\right)^{\frac{1+n}{2}}(n+2)}\left(\frac{E}{\sigma_{o}}\right)^{1-n}\left(\frac{2 R_{0}}{H}\right)^{1-n}\left(1-\beta \alpha^{n+2}\right)\right. \\
& \left.+\left(\left(\frac{2 R_{o}}{H}\right)^{3}\left(\frac{\sigma_{o}}{E}\right)^{3}(1-\beta)\right)\left(\frac{\left(1-\mathcal{V}^{2}\right)^{3}}{\left(1+\mathcal{V}^{2}-\mathcal{V}\right)^{\frac{3}{2}}}-\frac{3\left(1-\mathcal{V}^{2}\right)^{n+3}}{\left(\frac{3}{4}\right)^{\frac{1+n}{2}}(n+2)\left(1+\mathcal{V}^{2}-\mathcal{V}\right)^{\frac{n+2}{2}}}\right)\right)
\end{aligned}
$$

This is the equation of springback ratio using maximum shear stress (von Mises) theory for I-section where the plastic deformation is in the web. 


\section{Results and Discussion}

For bending I-sections the springback calculation for the previous two cases in Equations ((26), (30)). These Equations ((26) and (30)) are depending on the ratio $R_{o} / H, Y / E$ the strain hardening coefficient $(n)$, the geometrical coefficients $\alpha$, $\beta$ and the Poisson's ratio ( $v$ ).

Figure 3 and Figure 4 show the variation of springback ratio with the ratio $\left(R_{o} / H\right)$ for different values of $n$, strain hardening coefficient, at constant value of $\alpha=0.8, \beta=0.9$ with different values of $Y / E$ which are $1.522 \times 10^{-3}$ and $2.4 \times 10^{-3}$ (for different material 1100 al, 1065 steel) [16]. The range of the yield strain values $(Y / E)$ from $1.522 \times 10^{-3}$ to $2.4 \times 10^{-3}$, is recommended to investigate its effect on springback. It noticed that the springback ratio decreasing with increasing of $Y / E$ and increasing the values of strain hardening coefficient $(n)$.

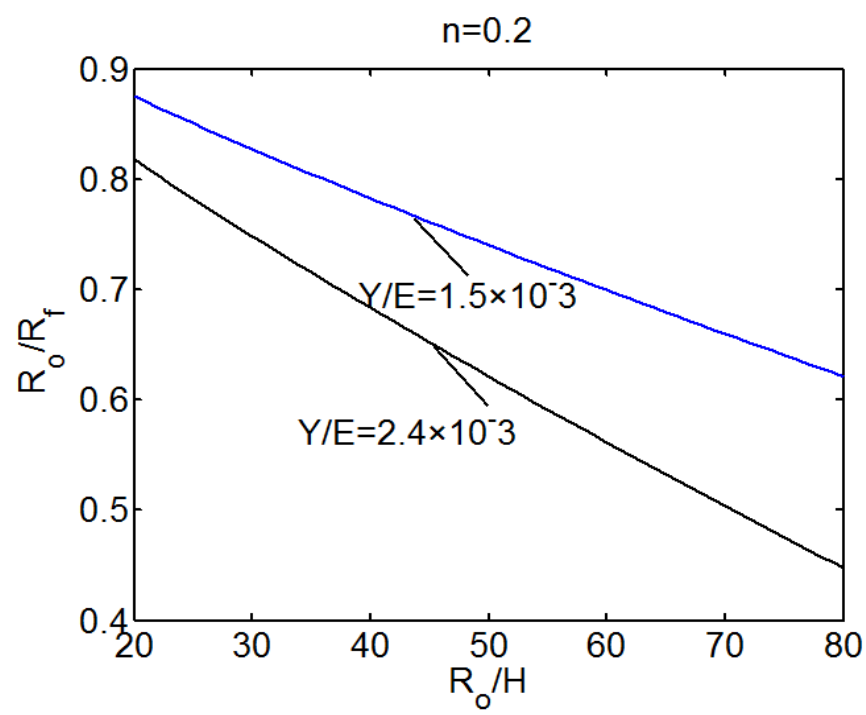

Figure 3. Springback ratio with $R_{o} / H$ with different values of $Y / E$ at $n=0.2, v=0.35$.

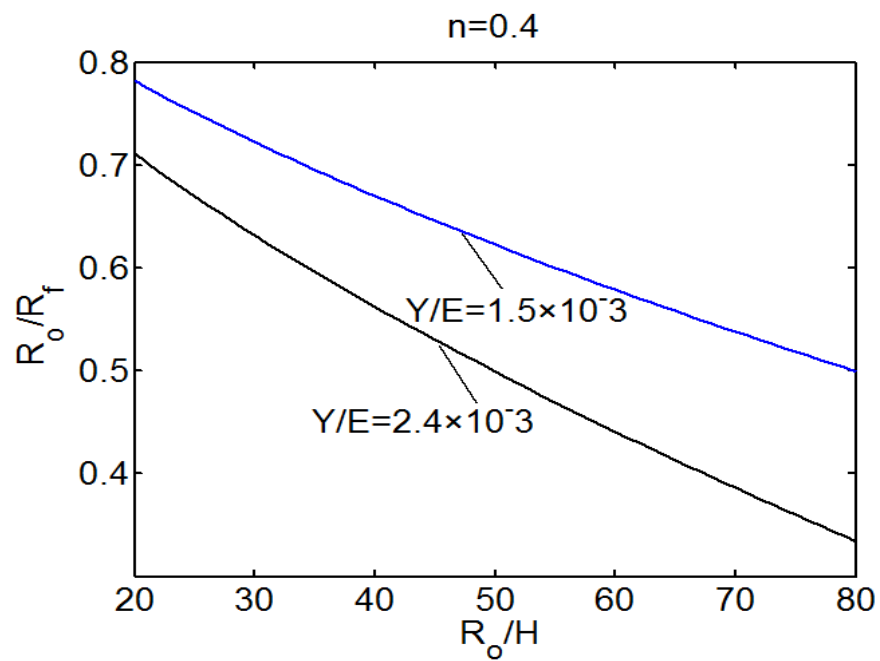

Figure 4. Springback ratio with $R_{o} / H$ with different values of $Y / E$ at $n=0.4, v=$ 0.35 . 
Figure 5 and Figure 6 show the variation of springback ratio with the $R_{d} / H$ ratio at different value of $Y / E$ at constant value of $\alpha=0.8, \beta=0.9$ with different values of $n$ (strain hardening coefficient. Figure 7 and Figure 8 show the variation of springback ratio at constant value of $\alpha=0.8$ and $\beta=0.9$ with different values of Poisson's ratio $(v=0.25,0.35,0.45)$ and at fixed value of $Y / E(1.522 \times$ $\left.10^{-3}, 2.4 \times 10^{-3}\right)$. From Figure 5 and Figure 6 , it is observed that the springback ratio decrease with the decreasing of Poisson's ratio and with the increasing of $Y / E$ ratio. Figure 9 and Figure 10 show the variation of radius of curvature after springback with different values of $H$ (the height of the beam) and different values of strain hardening coefficient $(n=0.2,0.4)$ at constant values of $R_{o}=40, \alpha=$ 0.8 and $\beta=0.9$. It is shown that the radius of curvature after springback is decreasing rapidly from rang 1 to $2 \mathrm{~mm}$ height, and then the decrease of the finial radius of curvature is become stable. In the next figures showed that: Figures 11-14 show the relation between radius of curvature before bending $R_{o}$ and

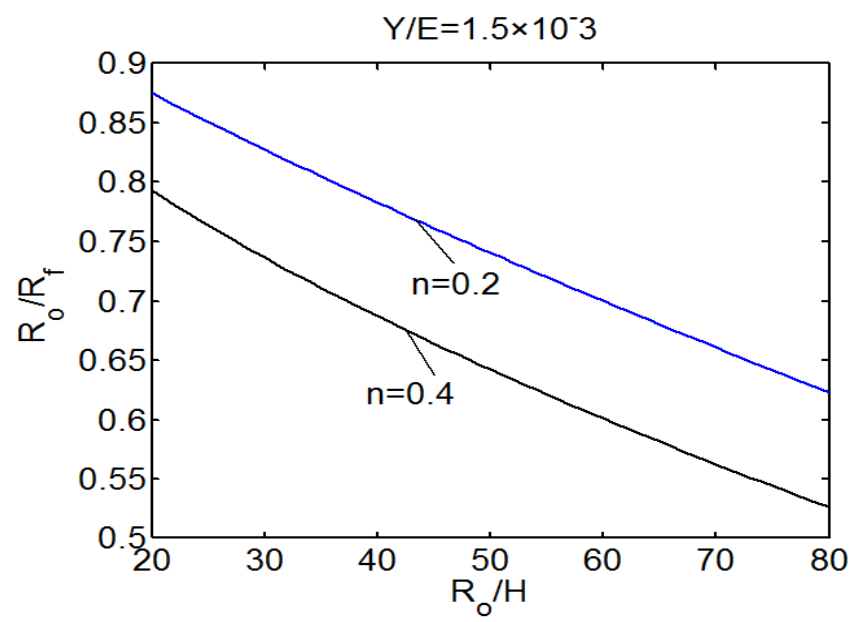

Figure 5. Springback ratio with $R_{d} / H$ with different values of $n$ at $Y / E=1.5 \times$ $10^{-3}, v=0.35$.

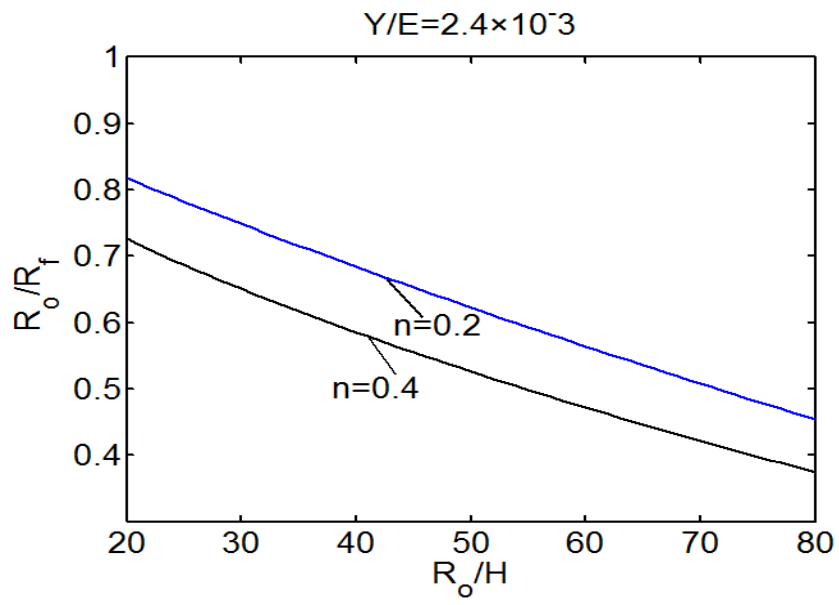

Figure 6. Springback ratio with $R_{d} / H$ with different values of $n$ at $Y / E=2.4 \times$ $10^{-3}, v=0.35$. 


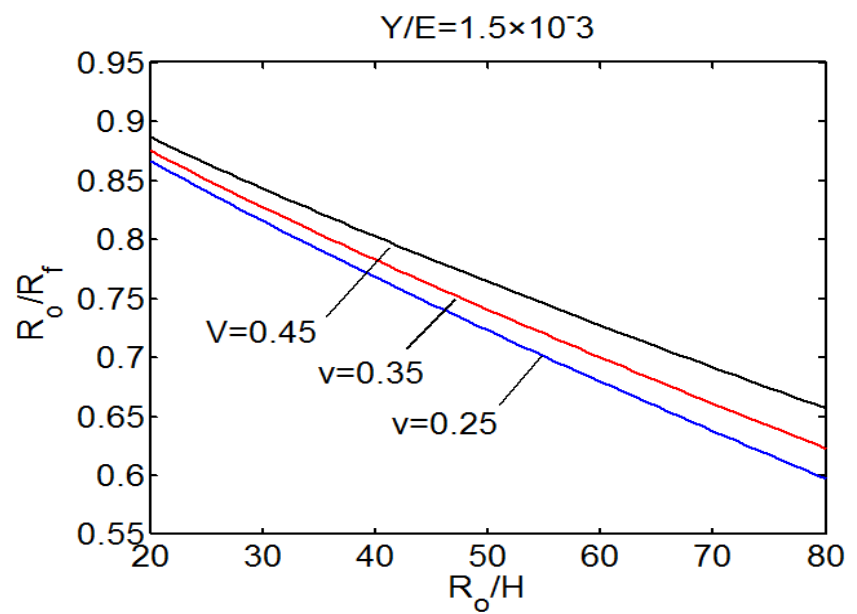

Figure 7. Springback ratio with $R_{d} / H$ with different values of $v$ at $Y l E=1.5 \times$ $10^{-3}, n=0.2$.

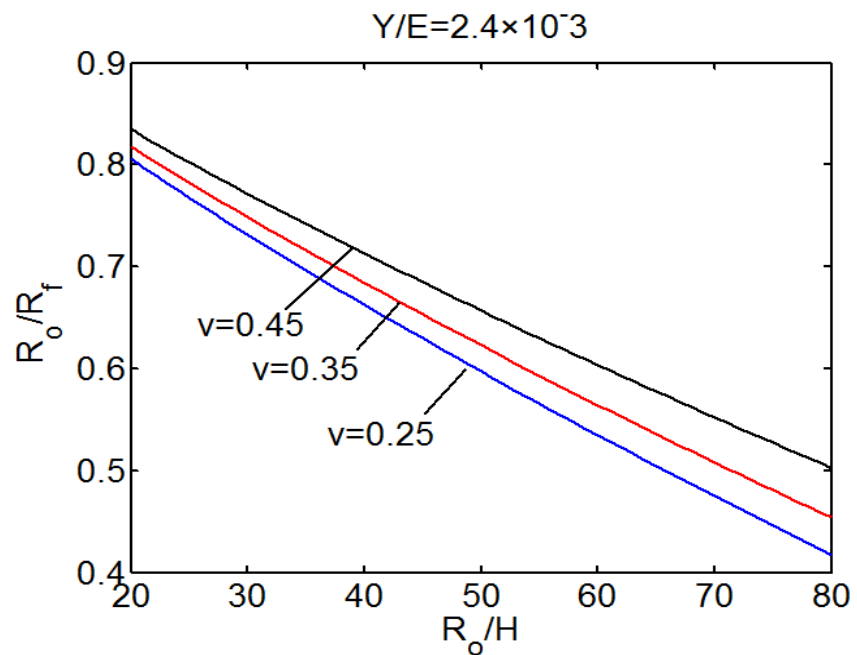

Figure 8. Springback ratio with $R_{d} / H$ with different values of $v$ at $Y / E=2.4 \times$ $10^{-3}, n=0.2$.

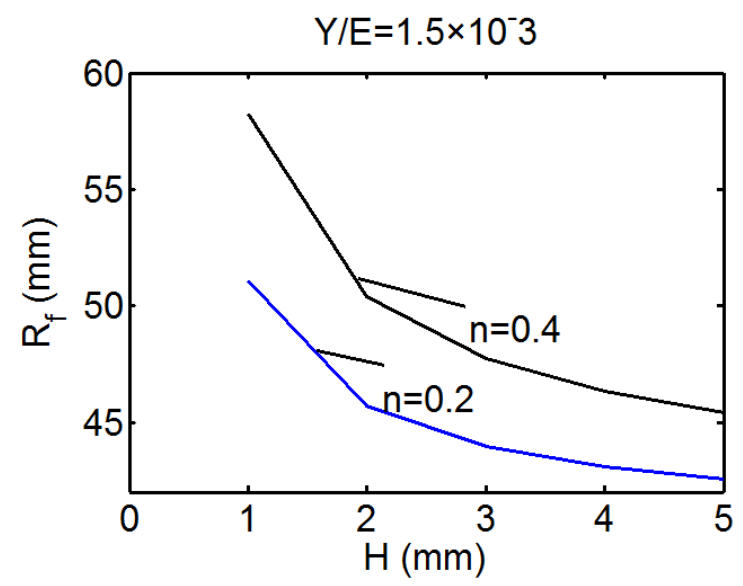

Figure 9. Springback ratio with $H(\mathrm{~mm})$ with different values of $n$ at $v=0.35$, $Y \mid E=1.5 \times 10^{-3}$. 


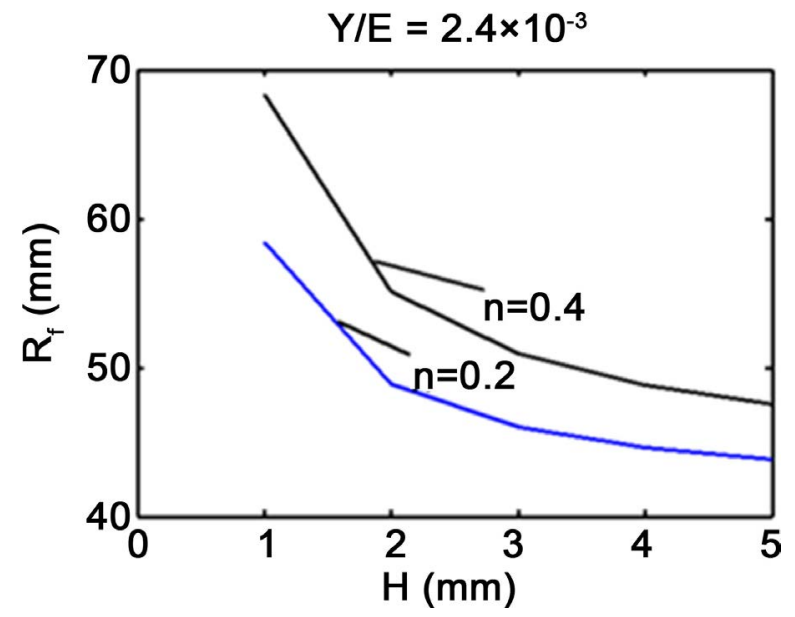

Figure 10. Springback ratio with $H(\mathrm{~mm})$ with different values of $n$ at $v=0.35$, $Y \mid E=2.4 \times 10^{-3}$.

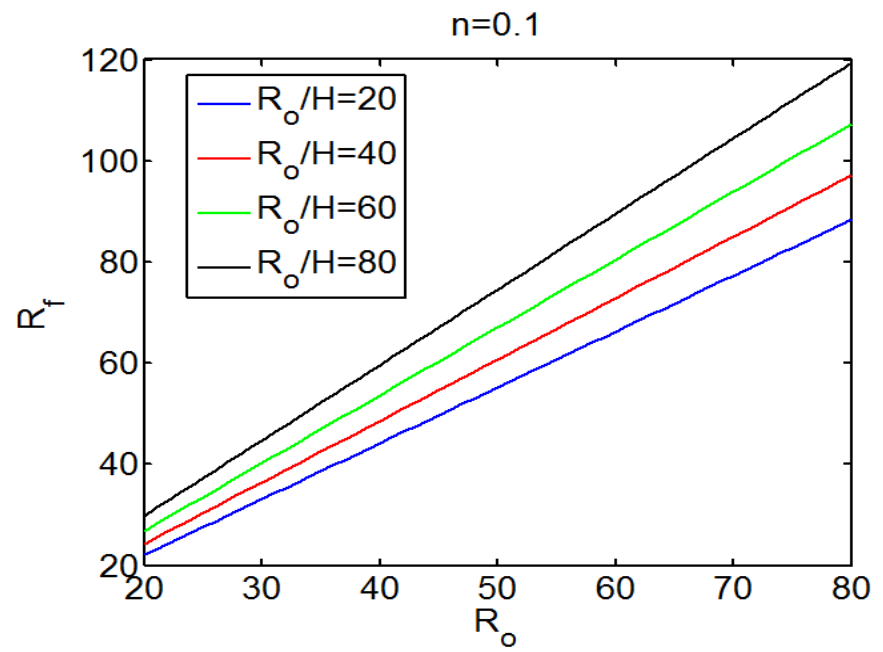

Figure 11. Relation between $R_{o}, R_{f}(\mathrm{~mm})$ at values of $R_{o} / H$ at $v=0.35, Y / E=1.5 \times 10^{-3}, n$ $=0.1$.

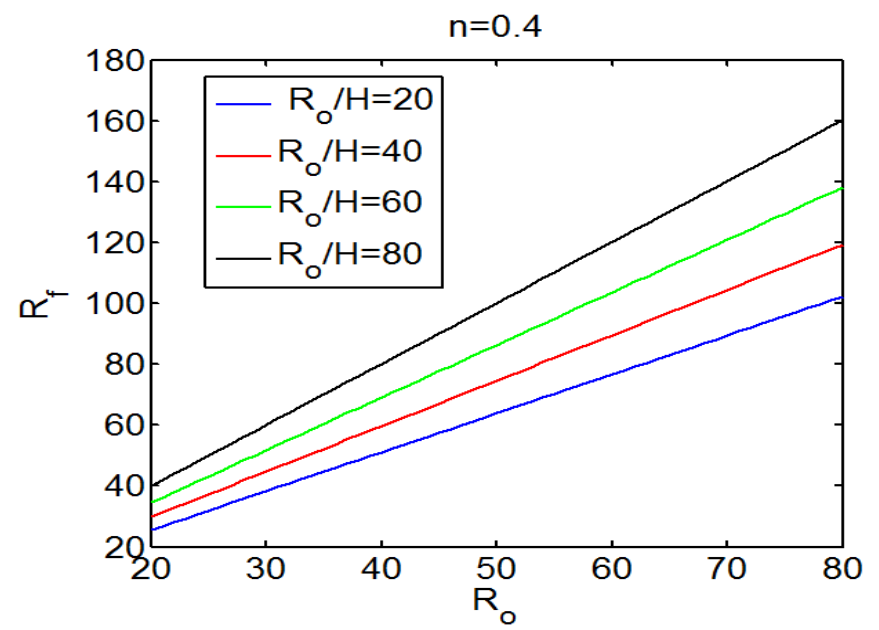

Figure 12. Relation between $R_{o}, R_{f}(\mathrm{~mm})$ at values of $R_{o} / H$ at $v=0.35, Y / E=1.5 \times 10^{-3}, n$ $=0.4$. 


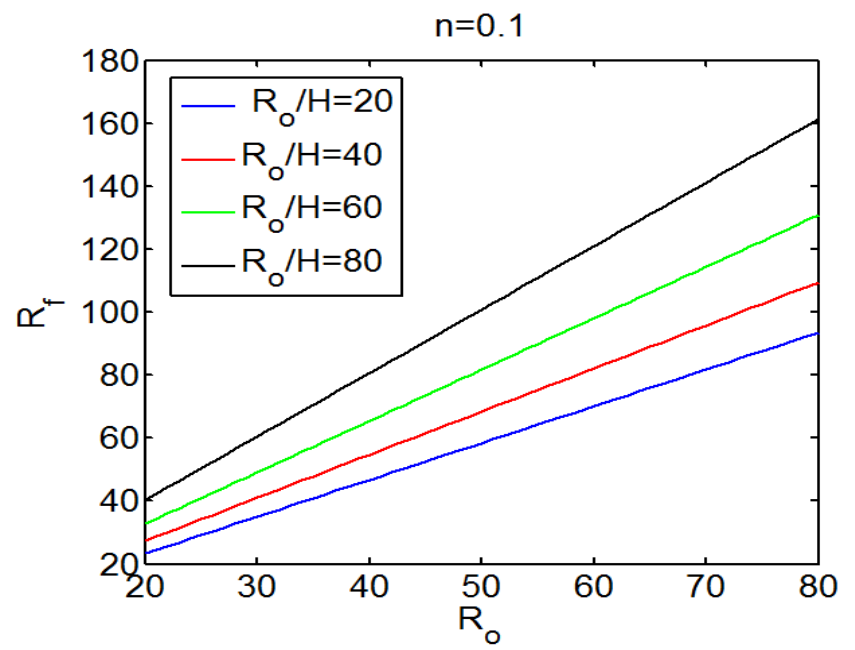

Figure 13. Relation between $R_{o}, R_{f}(\mathrm{~mm})$ at values of $R_{o} / H$ at $v=0.35, Y / E=2.4 \times 10^{-3}, n$ $=0.1$.

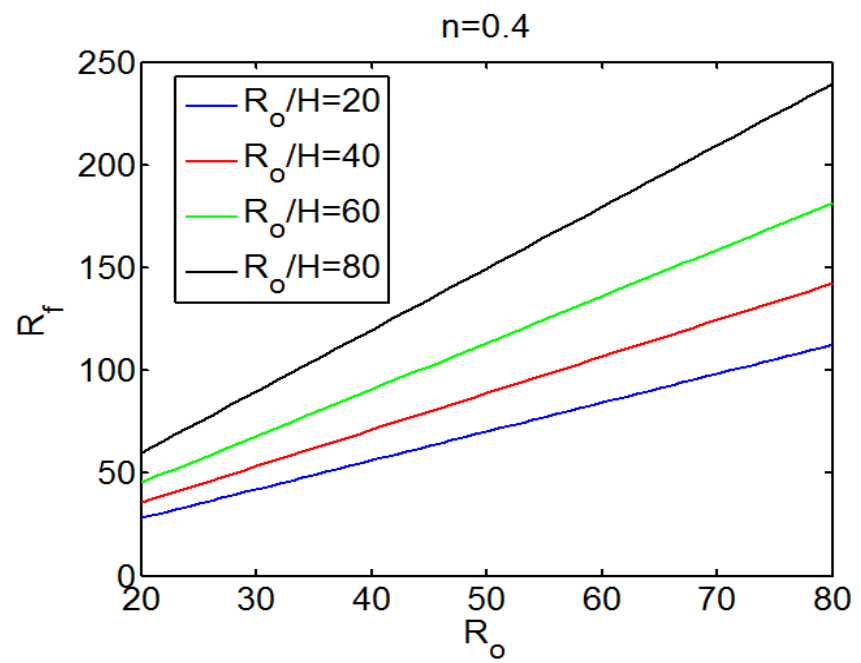

Figure 14. Relation between $R_{o}, R_{f}(\mathrm{~mm})$ at values of $R_{o} / H$ at $v=0.35, Y / E=2.4 \times 10^{-3}, n$ $=0.4$.

radius of curvature after bending $R_{f}$ it is noticed that the radius of curvature after bending $R_{f}$ is increase with the increase of $R_{o} / H$ ratio, the strain hardening coefficient $\mathrm{n}$ and decrease of $Y / E$ ratio at constant values of $\alpha=0.8, \beta=0.9$ and $v$ $=0.35$, also the radius of curvature after bending increase with the increase of radius of curvature before bending.

Mathematical model for springback equation with I-section beam is derived using Tresca in reference [15]. In this paper, a comparison between the springback equation according to Tresca and von Mises yield criteria has done. Figure 15 shows the comparison between springback equation using Tresca and von Mises criteria at $Y / E=2.4 \times 10^{-3}, n=0.1, \alpha=0.8, \beta=0.9$ and $v=0.25$. From this figure it is shown that the springback according to von Mises is little high than according to Tresca when $R_{\delta} / H$ is more than 60 for small values of $R_{\delta} / H$ (less than 


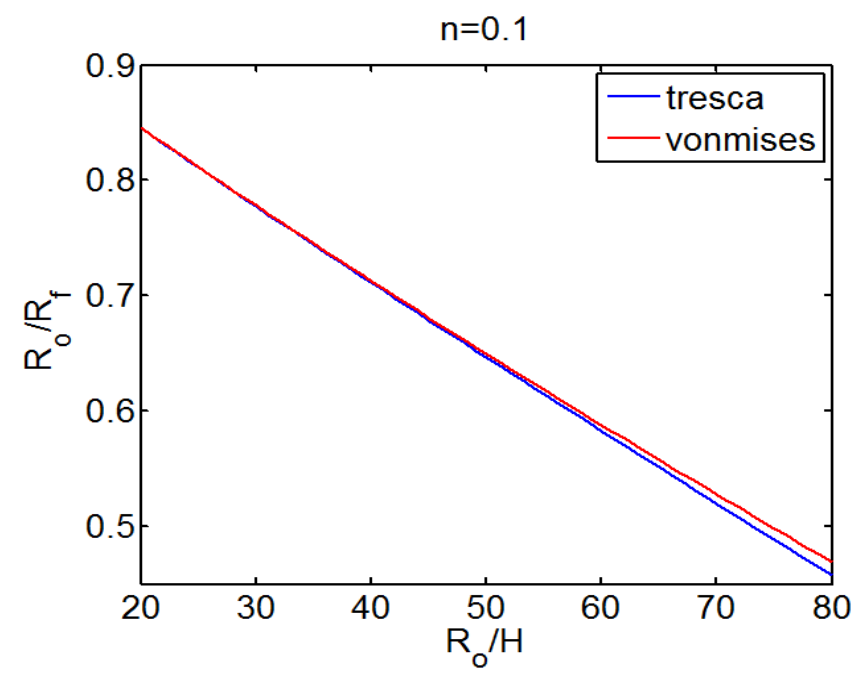

Figure 15. Comparison between Tresca and von Mises yielding criteria at $v=0.25, Y / E=$ $2.4 \times 10^{-3}, n=0.1$.

60) this difference is negligible. But using von Mises for very ductile materials is more useful.

\section{Conclusion}

The mathematical model of springback equations were derived in this paper according to von Mises yield criteria using nonlinear constitutive equation as the following conclusions: the theoretical analysis for I-section beam under bending has been carried out, and it was found that the prediction of springback is quite successful. Springback ratio increases with increasing Poisson's ratio. Springback ratio increases with increasing the beam height. Springback ratio increases with decreasing the ratio of yield point stress to young's modulus of elasticity. The springback is found to be more with decreasing values of strain hardening coefficient.

\section{References}

[1] Al-Qureshi, H. and Russo, A. (2002) Spring-Back and Residual Stresses in Bending of Thin-Walled Aluminium Tubes. Materials \& Design, 23, 217-222. https://doi.org/10.1016/S0261-3069(01)00061-9

[2] Ma, Z., Tong, G., Chen, F., Wang, Q. and Wang, S. (2015) Grain Size Effect on Springback Behavior in Bending of Ti-2.5 Al-1.5 Mn Foils. Journal of Materials Processing Technology, 224, 11-17.

https://doi.org/10.1016/j.jmatprotec.2015.04.025

[3] Fang, Z., Lu, H., Wei, D., Jiang, Z., Zhao, X., Zhang, X. and Wu, D. (2014) Numerical Study on Springback with Size Effect in Micro V-Bending. Procedia Engineering, 81, 1011-1016. https://doi.org/10.1016/j.proeng.2014.10.133

[4] Moon, Y., Kang, S., Cho, J. and Kim, T. (2003) Effect of Tool Temperature on the Reduction of the Springback of Aluminum Sheets. Journal of Materials Processing Technology, 132, 365-368. https://doi.org/10.1016/S0924-0136(02)00925-1

[5] El-Megharbel, A., El-Domiaty, A. and Shaker, M. (1990) Springback and Residual 
Stresses after Stretch Bending of Workhardening Sheet Metal. Journal of Materials Processing Technology, 24, 191-200. https://doi.org/10.1016/0924-0136(90)90181-S

[6] El Megharbel, A., El Nasser, G. and El Domiaty, A. (2008) Bending of Tube and Section Made of Strain-Hardening Materials. Journal of Materials Processing Technology, 203, 372-380. https://doi.org/10.1016/j.jmatprotec.2007.10.078

[7] Mertin, C. and Hirt, G. (2017) Numerical and Experimental Investigations on the Springback Behaviour of Stamping and Bending Parts. Procedia Engineering, 207, 1635-1640. https://doi.org/10.1016/j.proeng.2017.10.1091

[8] Leu, D.-K. and Hsieh, C.-M. (2008) The Influence of Coining Force on Spring-Back Reduction in V-Die Bending Process. Journal of Materials Processing Technology, 196, 230-235. https://doi.org/10.1016/j.jmatprotec.2007.05.033

[9] Manach, P.-Y. and Thuillier, S. (2012) Investigation of Springback of Metallic Sheets at Small Strains. Strain, 48, 216-224. https://doi.org/10.1111/j.1475-1305.2011.00814.x

[10] Panthi, S., Ramakrishnan, N., Ahmed, M., Singh, S.S. and Goel, M. (2010) Finite Element Analysis of Sheet Metal Bending Process to Predict the Springback. Materials \& Design, 31, 657-662. https://doi.org/10.1016/j.matdes.2009.08.022

[11] Zhao, J., Zhai, R., Qian, Z. and Ma, R. (2013) A Study on Springback of Profile Plane Stretch-Bending in the Loading Method of Pretension and Moment. International Journal of Mechanical Sciences, 75, 45-54. https://doi.org/10.1016/j.ijmecsci.2013.06.008

[12] Zhao, J., Zhai, R., Ma, R., Zhan, P. and Song, X. (2013) Springback Theory of Plane Bending and the Progress of Study on Its Engineering Application. Steel Research International, 84, 1230-1240. https://doi.org/10.1002/srin.201300029

[13] Song, Y. and Yu, Z. (2013) Springback Prediction in T-Section Beam Bending Process using Neural Networks and Finite Element Method. Archives of Civil and Mechanical Engineering, 13, 229-241. https://doi.org/10.1016/j.acme.2012.11.004

[14] Liu, T., Wang, Y., Wu, J., Xia, X., Wang, J., Wang, W. and Wang, S. (2015) Springback Analysis of Z \& T-Section 2196-T8511 and 2099-T83 Al-Lialloys Extrusions in Displacement Controlled Cold Stretch Bending. Journal of Materials Processing Technology, 225, 295-309. https://doi.org/10.1016/j.jmatprotec.2015.05.024

[15] Patel, S.K., Lal, R.K., Dwivedi, J.P. and Singh, V.P. (2013) Springback Analysis in Sheet Metal Forming Using Modified Ludwik Stress-Strain Relation. ISRN Mechanical Engineering, 2013, Article ID: 640958. https://doi.org/10.1155/2013/640958

[16] Leu, D.K. and Zhuang, Z.W. (2016) Springback Prediction of the Vee Bending Process for High-Strength Steel Sheets. Journal of Mechanical Science \& Technolo$g y$, 30, 1077-1084. https://doi.org/10.1007/s12206-016-0212-8

[17] Reham Saleha, G.A. and El-Megharbel, A. (2015) Determination of Springback Values in Bending I-Sections with Tresca. American Scientific Research Journal for Engineering, Technology, and Sciences, 14, 187-201. 